Research Article

\title{
Effect of L-Arginin to Repair Coronary Endothelial Heart Damage in Mice of Preeclampsia Model
}

\author{
Alip Sudarmono ${ }^{1}$, Sri Sulistyowati ${ }^{2}$, Supriyadi Hari Respati ${ }^{3}$, Asih Anggraeni ${ }^{4}$ \\ Department of Obstetrics and Gynecology, Faculty of Medicine, Sebelas Maret University/ \\ RSUD Dr. Moewardi Hospital, Surakarta \\ Coresponding Author: Sri Sulistyowati
}

Head Department of Study Obstetric and Gynecology Faculty of Medicine, Sebelas Maret University/ Hp: +62 812-2968-215/ Fax: 0271 665145/

\begin{abstract}
:
Background: Preeclampsia was thought to be caused by oxidative stress. Where there was an increased in lipoperoxidation products and nitric oxide synthase (NOS) and decreased antioxidants. L-Arginine through the nitric oxide line inhibit nitrite oxide synthase inhibitor causing vascular vasodilation. This study aimed to analyze the effect $L$-Arginine to repair endothelial damage: thickness and diameter of the coronary arteries in the heart of the mice preeclampsia model.

Methods: Experimental, 30 pregnant mice were randomly divided into three groups, in normal $10(\mathrm{~N})$, preeclampsia 10 (PE) and preeclampsia with $L$-Arginine 10 (PE-L). Preeclampsia mice were made by injecting anti-Qa2 $10 \mathrm{ng}$ ip on day 1 to $4^{\text {th }}$ day of pregnancy. L-Arginine was administered at a dose of $200 \mathrm{mg} / \mathrm{kgbw}$ from day 7 to day 15 . Termination in $16^{\text {th }}$ day, observation the histologic changes of the thickness and diameter coronary arteries. Statistics were used Kruskall Wallis test, followed by Mann Whitney's test.

Results: Mean coronary artery diameter of normal group was $1098,12 \mu \mathrm{m}$, preeclampsia $821,58 \mu \mathrm{m}$ with p=0,004 and preeclampsia with $L$-Arginine $991,27 \mu \mathrm{m}$ with $\mathrm{p}=\mathbf{0 , 0 1} 9$. Mean coronary artery diameter was normal 1098,12 $\mu \mathrm{m}$ compared to coronary artery diameter of preeclampsia with $L$ - Arginine $991,27 \mu \mathrm{m}$ with $\mathrm{p}=0,326$. Mean coronary artery thickness of normal group $178,13 \mu \mathrm{m}$, preeclampsia $235,29 \mu \mathrm{m}$ with $\mathrm{p}=\mathbf{0 , 0 0 9}$. Mean thickness of the coronary arteries of normal 178,13 $\mu \mathrm{m}$, compared to coronary artery thickness of preeclampsia with $L$-Arginine $169,96 \mu \mathrm{m}$ with p=0,669. Mean coronary artery thickness was $235,29 \mu \mathrm{m}$ preeclampsia compared to coronary artery thickness of preeclampsia with $L$ Arginine $169,96 \mu \mathrm{m}$ with $\mathrm{p}=0,002(\mathrm{p}<0,05)$.
\end{abstract}

Conclusions: L-Arginine effects of reducing coronary artery wall thickness and expanding diameter of heart coronary artery of preeclampsia mice model .

Key words: L-Arginine, the wall thickness of the coronary arteries, preeclampsia.

\section{INTRODUCTION}

Preeclampsia and its complications has become one of the causes of maternal morbidity and mortality in the world. This disease accounts for nearly $40 \%$ early delivery before 35 weeks' gestation. In addition, preeclampsia is strongly associated with an increased risk of fetal death. Preeclampsia occurs about $5-10 \%$ of all pregnant women around the world. ${ }^{1}$

Preeclampsia is the presence of hypertension and proteinuria in pregnant women over 20 weeks of gestation, with systolic blood pressure greater than $140 \mathrm{mmHg}$ and diastolic over 90 $\mathrm{mmHg}$. Proteinuria is defined by the presence of a dipstick protein of 1 or $300 \mathrm{mg} / 24 \mathrm{~h}$. This distinguishes with hypertension in pregnancy where hypertensive manifestation at 20 weeks' gestation without proteinuria is present. $^{2}$
In developing countries where access to adequate maternal health care is limited, maternal mortality can be as high as $15 \%$ when compared with developed countries of $0-1.8 \%$. In Indonesia $30-40 \%$ of cases of preeclampsia cause maternal mortality and $30-50 \%$ to cause perinatal death. ${ }^{3,4}$ At Dr. Moewardi Hospital Surakarta, maternal mortality in 2012 caused by preeclampsia were 19 people out of 30 pregnant women who died and in 2013 of which 12 of the 21 pregnant women who died. ${ }^{5}$

Placental preeclampsia produces superoxide in larger amount and less antioxidants than the normal placenta. Antioxidants level has also been reported decreases in women with preeclampsia. The release of placental debris also causes high 


\section{Sri Sulistyowati et al / Effect of L-Arginin to Repair Coronary Endothelial Heart Damage in Mice of Preeclampsia Model}

oxidative stress and endothelial dysfunction in preeclampsia. Placental disruption and uteroplacental ischemia induced microparticle placenta detached and into mother's blood circulation, these particles can cause inflammation and vascular damage. ${ }^{6}$

The pathology of the preeclamptic process through imbalance of angiogenic factors of complement and inflammatory activity contributes directly to cardiac stress. The cardiovascular structure and function will change that result in cardiovascular system dysfunction either systolic or diastolic function. Changes in vascular structures that will affect the incidence of heart disease in the long term less than 5 years. ${ }^{7}$

One early development of atherosclerosis is endothelial activation followed by endothelial dysfunction. In preeclampsia endothelial activation is thought to play an important role in the development manifestations preeclampsia patients. In preeclampsia endothelial dysfunction accompanied by excessive inflammatory response cause irreversible increasing tunica intima media. As a consequence there is decreasing vascular diameter due to vasoconstriction of blood vessels resulting in reduced blood flow. Vascular remodelling and accumulation of atherosclerotic plaque leads to hypertension in pregnancy. ${ }^{8}$

Endothelial damage by cardiovascular disease risk factors result in endothelial dysfunction with decreased production of nitrit oxide which activates a normal smooth muscle cells proliferate and migrate into intimate media tunica. This pathology contributes to the formation of atherosclerotic plaque . Hypertrophy

and vascular remodeling also contribute to vascular constriction appeared in women with a history of preeclampsia and air associated with an increased risk of cardiovascular disease. This mechanism contributes to increase risk of cardiovascular disease in the future in women who previously experienced preeclampsia. ${ }^{9}$

Epidemiological data show preeclampsia women has an increased risk of chronic hypertension and cardiovascular disease. Recurrent preeclampsia related with cardiovascular disease risk associated with a greater and women who suffer from preeclampsia before 34 weeks gestation, have an increased risk of cardiovascular death by 4 to 8 times greater than women whose pregnancies were normal. Overall, the risk of cardiovascular disease after preeclampsia increased 2 to 4 fold. ${ }^{9}$

L-Arginine is an essential amino acid found in proteins from the animal's body and various food sources. L-Arginine is derived from nitric oxide which is converted by the oxide nitrate synthase catalyst enzyme. L-Arginine has emerged as an important messenger intracellular and intercellular (Nitric oxide-cGMP) controlling many physiological processes. ${ }^{10}$

L-Arginine it has been mentioned that it has the role of the LArginine-nitrit oxyde pathway a in preeclampsia. Numerous studies have shown that the production of nitrit oyxde increases in normal pregnancy and plays an important role in mediating systemic hemodynamic and renal vasodilatation during pregnancy. In preeclampsia the occurrence of endothelial response in blood vessels. This suggests that endothelial NO production disorders can play an important role in mediating the pathophysiology of preeclampsia. $L$ Arginine is a substrate of nitric oxide (NO), a poten vasodilator, which has a role in blood pressure regulation. ${ }^{11}$

The purpose of this study was to determine the effect of $L$ Arginine to repair endothelial coronary artery damage of mice model preeclampsia .

\section{SUBJECT AND METHODS}

This study is an experimental study conducted at the Veterinary Faculty of Airlangga University. The sample size was based on the replication formula from Supranto, 30 samples. ${ }^{12}$ This sample divided randomly in three groups: normal pregnant mice, preeclampsia model and preeclampsia model with L-Arginine.

Samples using animals try Mus Musculus, with inclusion criteria, Mus Musculus female Swiss strain obtained from center Veterinaria Farma Surabaya 3 months age, healthy, weight 20 - 25 gram. Exclusion criteria in this study were mice who died during the study. All samples in doing synchronization surgery by injection 5 IU hormone Pregnant More Serum Gonadotropin (PMSG), 48 hours later injected 5 IU Human Chorionic Gonadotropin (hCG), then mated with male mice aged 7 months weight \pm 60 grams. The pregnant diagnosis was obtained 17 hours after mating with the sign of a copulatory plug.

On the $1^{\text {st }}$ day of pregnancy, the whole sample was divided into three groups, namely: to a normal group of 10 pregnant mice kept without intervention, pregnant mice preeclampsia model (on day 1 to day 4 of pregnancy given anti-Qa-2 as much $10 \mathrm{ng}$ iv to be a model of 10 preeclampsia mices.

On day $7^{\text {th }}-15^{\text {th }}$ pregnancy, $3^{\text {rd }}$ group is mice preeclampsia model given L-Arginine $200 \mathrm{mg} / \mathrm{kgBB}$ one day. On the $16^{\text {th }}$ day of pregnancy all the samples were terminated by surgery. Surgical procedures were performed under general anesthesia using intramuscular ketamine injection. Then do the sampling preparation of heart preparation of mice by the way the heart organ is fixed by using solution of Neutral Buffer Formalin $10 \%$ then cut and put into a specimen made of plastic. Furthermore, dehydration process in alcohol concentration of stratified that is al $\mathrm{k}$ ohol 70, 80, 90\% alcohol absolute I, absolute II each - 2 hours each. Then the xylol was clarified and then printed using paraffins so that the preparations are printed in paraffin blocks and stored in the refrigerator. Paraffin blocks are then cut thin as thick as 5-6 $6 \mathrm{~m}$ using a microtome. The pieces are floated in warm water temperature $60^{0} \mathrm{C}$ to stretch for the network does not multiply. Preparations conveniences expected ian lifted and placed in a glass object to be stained Hematoxylin Eosin (HE). Furthermore examined under a light Nikon E 100 microscope with 400x magnification digital camera is equipped with a 12 megapixel optilab plus calibrated, and the image processing software raster image 3 . The parameters assessed are sought histology of the coronary arteries is measured from thickness 
Sri Sulistyowati et al / Effect of L-Arginin to Repair Coronary Endothelial Heart Damage in Mice of Preeclampsia Model

Coronary artery diameter and coronary artery walls on three research groups namely normal pregnant mice, rats and mice models of preeclampsia models by administering L-Arginine with normal heart pregnant mice as controls. The diameter of the coronary artery is measured by the area of the circle, the thickness of the artery is measured to the tunica adventisia.

After all the samples were taken, the experimental animals were switched off by cervical dislocation in order to get the mice to die quickly so that the mice did not feel pain too long.

The reason for taking it on the 16th day is assumed to be the second trimester of pregnancy in human pregnancy, where in the second trimester the manifestations of preeclampsia appear in humans.

A data analysis using One Way Anova statistical test and Post Hoc t-Tests, Kruskal Wallis and Mann Whitney.

\section{FEASIBILITY OF ETHIC}

Ethical eligibility is obtained from research ethics commission Faculty of Veterinary Medicine Airlangga University Surabaya Number: 648 -KE , November 15, 2016.

\section{RESULTS}

\section{Thickness of Coronary Arthery}

Table 1 . Mean Coronary Artherial - thickness ( $\mu \mathrm{m})$

\begin{tabular}{llllll}
\hline \multicolumn{1}{c}{ Group } & Minimum & Maximum & Mean \pm SD & \multicolumn{2}{l}{ 95\% CIMean } \\
& & & & Lower & Upper bound \\
& & & & & \\
& & & & & \\
& & & & & \\
\hline Normal(N) & 95.25 & 239.60 & $178.17 \pm 44.37$ & 146.39 & 209.87 \\
Preeclampsia(PE) & 186.65 & 277.77 & $235.29 \pm 32.26$ & 212.22 & 258.37 \\
Preeclampsia with & 90.65 & 233.47 & $169.96 \pm 48.26$ & 135.44 & 204.25 \\
administration ofL- & & & & & \\
Arginine(PE-L) & & & & & \\
\hline
\end{tabular}

Table 1 shows coronary artherial thickness in normal group (N) mean value $178,17 \pm 44,37$. Mean value preeclampsia group (PE) equal to 235,29 $\pm 32,26$. Mean value of Preeclampsia with administration L-Arginine (L-PE) $169,96 \pm 48,26$.

Table 2. Thickness of Coronary Artery

\begin{tabular}{|c|c|c|c|}
\hline Group & Group Preclampsia & Group & Significant * $(p<0.05)$ \\
\hline $\operatorname{Nomal}(\mathrm{N})$ & $(\mathrm{PE})$ & $\begin{array}{l}\text { Preeclampsia with } \\
\text { administration of } \\
\text { L-Arginine (PE-L) }\end{array}$ & \\
\hline $178,13 \pm 44,37$ & $235,29 \pm 32,26$ & - & $0.009^{*}$ \\
\hline $178,13 \pm 44,37$ & - & $169,96 \pm 48,26$ & 0.669 \\
\hline- & $235,29 \pm 32,26$ & $169,96 \pm 48,26$ & $0.002^{\circ}$ \\
\hline
\end{tabular}

Table 2 shows that thickness coronary artery normal group $(\mathrm{N})$ and preeclampsia group (PE) have $\mathrm{p}=0.009$. Preeclampsia group (PE) and preeclampsia group with administration of $L$ Arginine (PE-L) have $\mathrm{p}=0,002$.

\section{Coronary Artery Diameter}

Table 3 . Mean Average Diameter Coronary Artery ( $\mu \mathrm{m})$

\begin{tabular}{lcrllr}
\hline Group & Minimum & Maximum & Mean \pm SD & \multicolumn{2}{c}{$95 \%$ CIMean } \\
& & & & Lower & Upper \\
& & & & Bound & Bound \\
\hline Nomal (N) & 558,40 & 1876,17 & $1098,12 \pm 345,33$ & 851,08 & 1345,16 \\
Preclampsia (PE) & 668,18 & 928,21 & $821,58 \pm 79,66$ & 764,59 & 878,56 \\
Preeclampsia with & 703,78 & 1406,40 & $991,27 \pm 202,13$ & 846,68 & 1135,86 \\
administration of & & & & & \\
\end{tabular}

L-Arginine (PE-L)

Table 3 shows that coronary diameter in normal group (N) mean values $1098,12 \pm 345,33$. Preeclampsia (PE) group mean value $821,58 \pm 79,66$. Preeclampsia with administration of $\mathrm{L}$ Arginine (L-PE) mean value 991,27 $\pm 202,13$.

Table 4. Coronary Artery Diameter

\begin{tabular}{|c|c|c|c|}
\hline Group $\operatorname{Nomal}(\mathrm{N})$ & Group & Group & Significant ${ }^{*}(\mathrm{p}<0,05)$ \\
\hline & Preclampsia(PE) & $\begin{array}{l}\text { Preeclampsia with } \\
\text { administration of } \\
\text { L-Arginine (PE- } \\
\text { L) }\end{array}$ & \\
\hline $1098,12 \pm 345,33$ & $821,58 \pm 79,66$ & - & $0,004^{*}$ \\
\hline $1098,12 \pm 345,33$ & - & $991,27 \pm 202,13$ & 0,326 \\
\hline - & $821,58 \pm 79,66$ & $991,27 \pm 202,13$ & $0,019^{*}$ \\
\hline
\end{tabular}

Table 4 shows that the diameter of the coronary artery between the normal group (N) and preeclampsia group (PE) have $p=0,004$. In the preeclampsia (PE) group with the preeclampsia group with L-Arginine (PE-L) have $\mathrm{p}=0,019$.

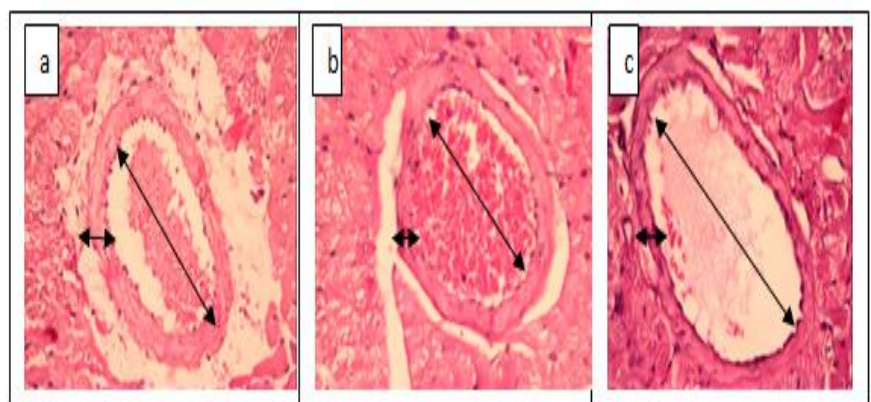

Figure 1. The thickness of the coronary artery in the heart of the mice with HE staining, 400x magnification.

In Figure 1 a) the branching of the coronary arteries in normal preganant mice appears a picture of thick coronary artery wall thickness and wide diameter. In figure b) branching of the coronary artery in mice of preeclampsia model shows a picture of coronary arteries with thick thickness and thickness of the 
wall compared with the thickness and diameter of the coronary artery in normal pregnant mice. In Figure c) coronary artery branching in mice of preeclampsia model by administration of $L$-arginin visible images of coronary arteries with thin wall thickness and wide diameter compared with thickness and diameter of coronary artery wall in mice of preeclampsia model.

\section{DISCUSSION}

In the preclinical phase of preeclampsia, hemodynamic vascular reactivity inhibition and left ventricular dysfunction is predominantly in women who tend to develop into preterm preeclampsia. In the second trimester there is a change in cardiac index decline associated with high vascular resistance index, increased mean arterial presure, intravascular contraction volume and decreased venous resistance capacity. $^{13}$

Preeclampsia preterm women also exhibit abnormal left ventricular remodeling patterns, usually concentric remodeling patterns and concentric hypertrophy. Preeclampsia women also show incidence of diastolic dysfunction and segmental abnormalities of myocardial relaxation. Diastolic failure is associated with increased left ventricular afterload and further remodeling as demonstrated by the increase mean arterial pressure significanly, total vascular resistance index, relative vascular wall thickening and left ventricular concentric hypertrophy. ${ }^{13}$

Longitudinal systolic function was also reduced in the preclinical phase of preeclampsia, whereas the sistolic radial function remain. Observations were supported by increased biomarkers of cardiovascular dysfunction, endothelial damage, and overall oxidative stress in women with preeclampsia. ${ }^{13}$

In this study mean diameter of the coronary artery between the preeclampsia group (PE) with the preeclampsia group with administration of $L$ - Arginine (PE-L) has significant difference $p=0,019$. It is also seen in coronary artery thickness between preeclampsia group (PE) with preeclampsia group with the administration of $L$ Arginine (PE-L) with a value of $\mathrm{p}=0,002$. This is likely due to the role of the L-Arginine system induced by nitric oxide, because the nitric oxide from the mother's circulation will pass into the placenta and dilate the coronary arteries by increasing the number of coronary artery vascularization, dilatation lumen and muscle walls of blood vessels so as not to have atherosis or thickening. ${ }^{10}$

Oxidative stress and lipid peroxidation give an impact such as occurrence of vascular endothelial dysfunction in women with preeclampsia. Antioxidants may be important for the prevention of lipid peroxidation and give hypothesis in preeclampsia prevention. ${ }^{14,15}$

Oxidative stress increases during preeclampsia and causes occurs the formation of lipid peroxide, reactive oxygen species and superoxide anion radicals caused endothelial dysfunction, placenta disfunction, platelet and neutrophil activation. $\mathrm{H}$ ipoksia placenta is a powerful stimulator of the endothelin synthesis and enhancing production of free radicals oxygen. L ipid peroxide will interfere with contractility and lead to reduced uterine blood flow utero placenta. In oxidation by free radicals and neutralization by antioxidants are kept in balance. But if the species of reactive oxygen (ROS) in excessive amounts, will cause oxidative stress that is suspected to be the cause of the pathogenesis preeclampsia. ${ }^{16,17}$

Endotel dysfunction associated with the disruption nitric oxide synthesis is considered one of the causes of hypertension in pregnancy. Cooke et al and $\mathrm{Wu}$ have found that administration of $L$-Arginine for pregnant women will increase the production of nitric oxide in peripheral vessels and reduce blood pressure. It has also been observed and gives good results on the use of L-Arginine for the treatment of arterial hypertension, hypertension related to pregnancy pathology, ischemic disease, circulatory failure, atherosclerosis, cerebral stroke. ${ }^{17}$

A preliminary study was conducted on mice showed that $L$ Arginine reduces the incidence of hypertension in response to a reduction in uterine perfusion pressure in pregnant mice . It showed that L-Arginine supplementation may be beneficial in the management of preeclampsia. In humans, administration of L-Arginine improves placental circulation, lowers maternal blood pressure and reduces platelet aggregation. ${ }^{18}$

Animal studies involving rats and mice that had been induced pre-eclampsia include hypertension, proteinuria and fetal growth restriction after inhibition of nitric oxide synthase activity NG-nitro-L-Arginine methyl ester (L-NAME) is an important inhibitor of nitric oxide synthase. This condition seems to have improved after therapy with L-Arginine ie reduced urinary protein excretion, decreased blood pressure significant and restore abnormal glomeruli lesions. L-Arginine act through nitric oxide synthase pathway by inhibiting nitric oxide synthase inhibitors that nitric oxide production will increase and provide the right impact and improve vascular hypoxic vasodilation. ${ }^{19}$

Other studies have shown that in mice models without prior risk factors, the incidence of preeclampsia during pregnancy increases the response of vascular remodeling to future lesions. The vascular response to this lesion in rats increases after preeclampsia altough has normalized non invasive cardiovascular parameters after labor as in women with preeclampsia. This supports a new paradigm where preeclampsia causes a change in vascular physiology that increases the response to future vascular damage that may be mediated by existing risk factors as well as new risk factors in women with a history of preeclampsia. ${ }^{8}$

\section{LIMITATIONS OF RESEARCH}

In this study, the researchers did not describe the phenotype of mice who had experienced preeclampsia and the researchers also did not control the stress factors of mice due to multiple injections, especially in the mice group of pregnant models of preeclampsia with the administration of L-arginin. 


\section{CONCLUSION}

L-Arginine effect of reducing wall thickness and expanding diameter of heart coronary artery in mice of preeclampsia model.

\section{CONFLICT OF INTEREST STATEMENTS}

The authors state there is no conflict of interest in relation to the research, writing and or publication of this article

\section{ACKNOWLEDGEMENT}

Our thanks go to the head and staf of Veterinary reproduction laboratory of the Faculty of Veterinary Medicine UNAIR

\section{REFERENCES}

[1] Valenzuela F.J, Perez-Sepulveda A, et al. Pathogenesis of Preeclampsia: The Genetic Component. Journal of Pregnancy. Volume 2012 (2012).

[2] Mongraw-Chaffin M.L, Cirillo P.M, Cohn B.A.Preeclampsia And Cardiovasculer Desease Death: Prospective Evidence From The Child Health And Development Studies Cohort. Hypertension. 2010.Jul;56(1):166-71.

[3] Staff A.C, Benton S.J et al. Redefining Preeclampsia Using Placenta - Derived Biomarkers. Hypertension. 2013;61:932-942.

[4] Sulistyowati S, Abadi A, Hood J. The Influence of Low HLA-G Protein Expression on HSP-70 and VCAM-1 Profile in Preeclampsia.Indonesian J Obstet Gynecol.2010.Vol 34(4).185-190.

[5] Sulistyowati S, Soetrisno S, Nizar H.K. Expression of Human Leukocyte Antigen-C in Trophoblast and Natural Killer Cell in Decidua on Severe Preeclampsia. Jurnal Kedokteran Brawijaya. 2016.Vol. 29, No. 1.P;59-63.

[6] Powe C.E, Levine J.R, Karamunchi S.A. Preeclampsia a Disease of The Maternal Endothelium: The Role of Antiangiogenic Factors and Implications for Later Cardiovascular Disease. Circulation. 2011. Jun 21;123(24):2856-69.

[7] Ida B, Saima B, et al. Association Between Hipertension Disorder Of Pregnancy And Later Risk Cardiomiopati. JAMA. 2016. Mar 8;315(10):1026-33.

[8] Blaauw J, Souwer E.T et al. Increased Intima Media Thickness After Early Onset Preeclampsia. Obstet Gynecol. 2006. Jun;107(6):1345-51.

[9] Pruthi D, Khankin E.V,et al. Exposure to Experimental Preeclampsia in Mice Enhances The Vascular Response to Future Injury. Hypertension. 2015.Apr;65(4):863-70

[10] Al-Bayati M.A, Ahmad A.M, Khamas W. The Potential Effect of L-Arginine on Mice Placenta. Avdvance Pharmocoepidemiology Safety Journal. 2014.Vol 3, Issue 2, P: 1-9.

[11] Camacho E, Maria G.M, Maria D.R.G, Anita I. Rat Kidney Antioxidant Enzyme Activities In Experimental
Preeclampsia, Israel Laboratory of Neuropeptides, School of Pharmacy, Universidad Central de Venezuela, Caracas, Venezuela. Published online August 28. International Journal Pharmaceutical Research. 2015.Vol. 1, issue 7, P:104-109.

[12] Supranto, J. Teknik Sampling untuk Survei dan Eksperimental. Penerbit: PT. Rineka Cipta, Jakarta. 2000.

[13] Karen M, Rajan S, Basky T. Cardiovasculer implication in preeclampsia an over view. Circulation. 2014. Aug 19;130(8):703-14.

[14] Sales A.M.R, Galvao T.F, Pereira M.G. Antioxidants for Preventing Preeclampsia : A Systematic Review. The Sceintific World Journal. 2012.P:1-11.

[15]Lucca L, Gallarretta F.M.P, Goncalves T.D.L. Oxidative Stress Markers in Pregnant Woman with Preeclampsia. American Journal of Medical and Biological Research. 2015. Vol. 3, No. 3, P:68-73.

[16] Begum R. Lipid Peroxidation and Antioxidant Status in Preeclampsia. J. Enam Med Col 2011 : 1 ( 2 ). P: 56 - 59.

[17] Grafka A, Maciej T. Study of The Role L-Arginine in the Diagnosis of Pregnancy-Induced Hypertension. Viamedica. 2016.Vol. 20, No. 3, P: 113-118.

[18] Jaramillo P.L, Arenas W.D, Garcia R.G, Rincon M.Y, Lopez M. The Role of The L-ArginineNitric Oxide Pathway in Preeclampsia. Ther Adv Cardiovasc Dis . 2008. P: 261-275.

[19] Dorniak-Wall T, Grivel R.M, Dekker G.A, Hague W, Dodd J.M. The Role of L-Arginine in The Prevention and Treatment of Pre-eclampsia: a Systematic Review of Randomized Trials. J Hum Hypertens. 2013. P: 230-235. 